\title{
Current Status of Schistosoma mansoni Infections and Associated Risk Factors among Students in Gorgora Town, Northwest Ethiopia
}

\author{
Tarko Essa, ${ }^{1}$ Yemane Birhane, ${ }^{2}$ Mengistu Endris, ${ }^{3}$ Asmeret Moges, ${ }^{2}$ and Feleke Moges ${ }^{3}$ \\ ${ }^{1}$ Pathfinder International, Addis Ababa, Ethiopia \\ ${ }^{2}$ Addis Continental Institute of Public Health, Addis Ababa, Ethiopia \\ ${ }^{3}$ Department of Medical Microbiology, School of Biomedical and Laboratory Sciences, College of Medicine and Health Sciences, \\ University of Gondar, P.O. Box 196, Gondar, Ethiopia
}

Correspondence should be addressed to Mengistu Endris; mengistu06@gmail.com

Received 13 September 2012; Accepted 8 October 2012

Academic Editors: H. Hisaeda and M. Vaillant

Copyright (C) 2013 Tarko Essa et al. This is an open access article distributed under the Creative Commons Attribution License, which permits unrestricted use, distribution, and reproduction in any medium, provided the original work is properly cited.

\begin{abstract}
Background and Objective. Schistosomiasis is highly prevalent in tropics and causes morbidity and mortality in developing countries including Ethiopia. This study is aimed to assess the current status of $S$. mansoni infections and associated risk factors among students in Gorgora town, Northwest Ethiopia. Method. A cross-sectional study was conducted from October 2010 to November 2010 at Gorgora, Northwest Ethiopia. All students (579) present during the study period were enrolled. Pretested questionnaires were used to collect sociodemographic data and predisposing factors. Stool examination was performed using wet mount and KatoKatz techniques. Data were entered and analysed using SPSS version 20.0 statistical software. Result. Among 579 students enrolled, 291 (50.3\%) were positive for one or more intestinal parasites. Prevalence of S. mansoni was found to be $20.6 \%$ with mean intensity of infection (125 eggs per gram of feces). Lack of awareness and water contact habits such as frequent swimming in the open water source, agricultural activities on bare foot, and washing clothes were also associated with high risk of $S$. mansoni infection. Conclusion. Even though there seems to be a decline in the prevalence of $S$. mansoni infections in the study area, the problem still persists and affects students significantly. Therefore, therapeutic intervention and health education are needed.
\end{abstract}

\section{Background}

Schistosomiasis is a parasitic disease that leads to chronic infection. The disease is prevalent in 75 countries of the world [1]. Globally 500-600 million people are at risk of infection and 200 million peoples are infected with schistosomiasis; $85 \%$ of the cases are found in 41 countries of Africa [2]. In Ethiopia and Eritrea the population living under the risk of infection with Schistosoma mansoni (S. mansoni) was estimated to be 19 million [3].

Human infection is initiated during water exposure (planting, fishing, washing, and swimming) that contains the free-living infective stage of the parasite, cercaria. Different strategies have been used to prevent this debilitating disease. The primary health care approach has been used by a number of countries in Africa and other endemic regions of the world. It was based on the fact that development of irrigation schemes, dam construction for hydroelectric power, water conservation for different purposes, human behaviours such as swimming habits and improper waste disposal, poverty like use of river water for different purposes, and wide distribution of intermediate host were identified as the major contributing factors for the increased prevalence and wide distribution of schistosomiasis [4].

Patients infected with S. mansoni develop granuloma around the egg and the Schistosoma antigens in the intestine and liver. The granuloma is followed by fibrosis, and chronic inflammation in the liver, leading to portal hypertension, causing liver disease, ascites, and oesophagogastric haemorrhage [5]. Renal failures due to antigen antibody complex and exposure to secondary bacterial or viral infection were observed in some chronically infected individuals [6]. 
Schistosomiasis like other neglected diseases is a disease of poverty [7]. It is mostly prevalent in sub-Sahara Africa, where not only it overlaps with other few low priority diseases but also high priority diseases such as HIV, malaria, and tuberculosis [8]. Schistosomiasis has low mortality but high morbidity rates and because of prioritization, the high mortality diseases are treated first $[7,8]$. Praziquantel is primarily used for treating people with $S$. mansoni infections [4]. It is helpful not only to recognize the prevalence of schistosomiasis but also identify the risk factors of schistosomiasis. A review of literatures on prevalence of $S$. mansoni documented rates that range from less than $1 \%$ up to more than $90 \%$ in Ethiopia [9]. This study is aimed to provide the current epidemiological information on S. mansoni and associated risk factors among students in Gorgora town, Northwest Ethiopia.

\section{Methods}

2.1. Study Design. A cross-sectional study was conducted among students in Gorgora town, Northwest Ethiopia from October 2010 to November 2010.

2.2. Study Area. Gorgora is a small road side town on the shore of Lake Tana with elevation (altitude) 1800 meters, $65 \mathrm{~km}$ south of Gondar town, $2.89 \mathrm{~km}$ square area, with annual rain fall $1038 \mathrm{~mm}$ and population size 2500 (Dembia district). Their economy depends primarily on trading, farming, fishing, gathering the fuel wood, and others are retired soldiers.

2.3. Study Population. All 579 students who attended in Gorgora Elementary school were included in the study.

2.4. Data Collection. Sociodemographic data which include sex, age, parental occupation, and educational status and other necessary information were gathered using pretested structured questionnaires. Risk factors of S. mansoni infection like swimming habit, washing clothes and utensil in open water source, water contact during agricultural activities on bare foot, and source of water for drinking were assessed. Eight teachers (home room teachers for each class room) were selected and trained how to conduct interviews. Students were interviewed for the presence or absence of signs and symptoms of $S$. mansoni infection like bloody stool, bloody diarrhoea, abdominal discomfort, and whether treated for the previous infection or not.

2.5. Stool Collection and Parasitic Examination. Each student was provided with labeled, clean, dry, and leak proof stool cup to bring about $5 \mathrm{gm}$ of fresh stool. About $20 \mathrm{mg}$ of stool sample was processed at Gorgora Clinic laboratory using direct saline preparation for microscopic examination of $S$. mansoni and other intestinal parasites. To determine intensity of infections for S. mansoni and other common helminthes, $41.7 \mathrm{mg}$ of stool sample was processed using Kato thick smear [2]. The parasite load was defined as light, moderate, and heavy based on the number of eggs per gram of stool (EPG) for S. mansoni and other common helminthes according to WHO guideline [2].

2.6. Quality Control. All the necessary reagents were checked by known positive and negative samples before sample preparation and examination. The smears were examined independently with two experienced laboratory technologists and $10 \%$ of the total slides were randomly selected and read by a third experienced laboratory technologist working at the University of Gondar.

2.7. Data Analysis. For data entry and analysis SPSS version 20.0 statistical software was used. Overall and sex-specific prevalence were calculated using descriptive statistics of the sample through frequencies and cross tabulations. Strength of association between $S$. mansoni infection and various risk factors was calculated by bivariate analysis. Association was analyzed by multivariate logistic regression to show the cofounding effect and calculating the odds ratios (OR) with 95\% confidence intervals $(\mathrm{CI})$.

2.8. Ethical Consideration. Ethical clearance was obtained from ethical clearance committee of University of Gondar and permission from Amhara Regional Health Bureau and local education authority of the schools to conduct the study. Informed verbal consent was obtained from each study participant and their parent/guardian. The students who were found positive for $S$. mansoni and other intestinal parasites were treated with the standard regimen.

\section{Results}

A total of 579 students with age ranged from 7 to 24 (median age of 12) were enrolled in the study. Of the total subjects 293 $(50.6 \%)$ were males and $286(49.4 \%)$ were females. Out of this 293 (50.6\%) were from Gorgora town and 286 (49.4\%) from rural areas around Gorgora (Table 1).

The overall prevalence rate for all intestinal parasites was $291 / 579$ (50.3\%). The most frequent parasites encountered in the present study were S. mansoni and Ascaris lumbricoides followed by Hymenolepis nana and Giardia lamblia and others less than $5 \%$ (Table 2). The highest prevalence of intestinal parasite was observed in the age range of 5-9 years (54\%), followed by $10-14$ years (52\%). Among study subjects, $53.3 \%$ of males and $47.2 \%$ females were found to be positive for one or more intestinal parasites (Table 2).

The prevalence of $S$. mansoni in this study was found to be $20.6 \%$. The highest prevalence of S. mansoni was obtained from urban areas $23.9 \%(70 / 293)$. Twenty two percent of females and $18.4 \%$ of males were found to be positive for S. mansoni. The distribution of S. mansoni infection with age groups showed that 15-19 (22\%) of ages were more affected, followed by age group 10-14 (20\%). S. mansoni infection was statistically associated with high prevalence in rural areas and school grade level (5-8). However, sex, age, parent educational status, and parent occupation were not statistically significant (Table 1). 
TABLE 1: Distribution and association of $S$. mansoni by sociodemographic data among students $(n=579)$ of Gorgora Elementary School, Northwest Ethiopia, October 2010-November 2010.

\begin{tabular}{|c|c|c|c|c|c|}
\hline Sociodemographic data & Total $(n=579)$ & Positive (S. mansoni) & $P$ value & COR [95\% CI] & AOR [95\% CI] \\
\hline \multicolumn{6}{|l|}{ Residence } \\
\hline Urban & $293(50.6)$ & $70(23.9)^{*}$ & 0.047 & $1.51[1.00,2.28]$ & $1.89[1.00,3.33]$ \\
\hline Rural & $286(49.4)$ & $49(17.1)$ & & 1.00 & \\
\hline \multicolumn{6}{|l|}{ Sex } \\
\hline Male & $293(50.6)$ & $54(18.4)$ & 0.217 & 1.00 & \\
\hline Female & $286(49.4)$ & $65(22.7)$ & & $1.30[0.87,1.95]$ & $131[0.86,1.99]$ \\
\hline \multicolumn{6}{|l|}{ Age } \\
\hline $5-9$ & $100(17.3)$ & $15(15.0)$ & 0.087 & $3.09[0.99,9.63]$ & $2.73[1.95,14.0]$ \\
\hline $10-14$ & $330(57.0)$ & $69(20.9)$ & & $2.06[0.73,5.77]$ & $2.70[2.20,5.07]$ \\
\hline $15-19$ & $132(22.8)$ & $29(22.0)$ & & $1.94[0.66,5.66]$ & $2.51[2.01,3.37]$ \\
\hline $20+$ & $17(2.9)$ & $6(35.3)$ & & 1.00 & \\
\hline \multicolumn{6}{|c|}{ Educational status of respondents (grade) } \\
\hline $1-4$ & $209(36.1)$ & $32(15.3)$ & 0.03 & 1.00 & \\
\hline $5-8$ & $370(63.9)$ & $87(23.5)$ & & $1.70[1.09,2.66]$ & $2.64[1.49,4.66]$ \\
\hline \multicolumn{6}{|l|}{ Father education } \\
\hline Unable to write and read & $150(25.9)$ & $25(16.7)$ & 0.208 & $0.71[0.44,1.16]$ & $0.82[0.47,1.45]$ \\
\hline Able to write and read & $429(74.1)$ & $94(21.9)$ & & 1.00 & \\
\hline \multicolumn{6}{|l|}{ Mother education } \\
\hline Unable to write and read & $290(50.1)$ & $55(19.0)$ & 0.358 & 1.00 & \\
\hline Able to write and read & 289 (49.9) & $64(22.1)$ & & $0.82[0.55,1.23]$ & $0.93[0.56,1.50]$ \\
\hline \multicolumn{6}{|l|}{ Father job } \\
\hline Government employee & $370(63.9)$ & $81(21.9)$ & 0.288 & $1.29[0.82,2.03]$ & $1.01[0.85,2.50]$ \\
\hline Farmer, fisher, daily laborer & $209(36.1)$ & $38(18.1)$ & & 1.00 & \\
\hline \multicolumn{6}{|l|}{ Mother job } \\
\hline House wife & $442(76.3)$ & $86(19.5)$ & 0.281 & $0.76[0.48,1.48]$ & $0.60[0.30,7.53]$ \\
\hline Daily laborer & $137(23.7)$ & $33(24.1)$ & & 1.00 & \\
\hline
\end{tabular}

${ }^{*}$ Figures in parenthesis indicate percentages.

Risk factors assessment for S. mansoni infection showed that open water contact habits such as swimming, washing clothes and utensil in open water sources, frequent swimming, bare foot during agricultural activities, and low awareness of bilharziasis were associated with high risk of schistosomiasis infection (Table 3).

Multiple logistic models were performed for variables that were significantly associated with S. mansoni from bivariate analysis. In urban areas $S$. mansoni infection was 1.89 times (95\% CI: $1.07,3.3)$ more likely than rural students. After adjusting for urban areas, in grade 5-8 students, open water contact practice such as swimming, washing clothes and utensil in open water sources, frequent swimming, bare foot during agricultural activities, and low awareness of bilharziasis remained significant association with S. mansoni (Table 3).

Students from grades 1-4 and 5-8 were compared for $S$. mansoni infection. Students with a habit of washing clothes were 15.9 times (95\% CI: 3.86, 65.40) more likely to acquire S. mansoni infection. Students washing utensils were 2.076 times (95\% CI: $1.19,3.62)$ more likely to acquired S. mansoni infection. Students with bare foot during agricultural activities were 7.08 times 95\% CI: 3.82, 13.12) more likely to acquire $S$. mansoni infection. Students swimming in open water were 4.51 times (95\% CI: $1.38,14.73$ ) more likely to acquire S. mansoni infection. Students with no knowledge of bilharziasis were 20.36 times (95\% CI: 8.16, 50.78) more likely to acquire $S$. mansoni infection. Generally, students who have more access to open water contact habits (i.e., grade 5-8) were 2.64 times $(95 \% \mathrm{CI}: 1.49,4.66)$ more likely to acquire S. mansoni infection (Table 3 ).

The intensity of $S$. mansoni infection showed that predominantly light infection $76(13.1 \%)$ with the egg count ranged from 1-99 eggs per gram of feces, the rest (41 (7.1\%) and $2(0.3 \%))$ was considered as moderate (100-399 EPG) and heavy infections (>399 EPG), respectively, (Table 4). The mean intensity of infection was 125.8 EPG. Analysis of the intensity of infection in the age groups showed the peak of light infections to be in the age group 15-19. The intensity decreased in the age group 10-14 and the least affected were 5-9-year-old children.

\section{Discussion}

Schistosomiasis is the most prevalent helminthic infection in tropics and subtropics mainly in sub-Saharan countries 
TABLE 2: Prevalence of intestinal parasites among male and female students $(n=579)$ of Gorgora Elementary School, Northwest Ethiopia, October 2010-November 2010.

\begin{tabular}{|c|c|c|c|c|}
\hline Intestinal parasites & $\begin{array}{c}\text { Male } \\
n=239\end{array}$ & $\begin{array}{c}\text { Female } \\
n=286\end{array}$ & $\begin{array}{c}\text { Total } \\
(n=579)\end{array}$ & $\begin{array}{c}P \text { value } \\
(95 \% \mathrm{CI})\end{array}$ \\
\hline Schistosoma mansoni & $54(18.4)^{*}$ & $65(22.7)$ & $119(20.6)$ & $0.20(0.18,0.24)$ \\
\hline Ascaris lumbricoides & $55(18.8)$ & $54(18.9)$ & $109(18.8)$ & $1.00(0.99,1.0)$ \\
\hline Hymenolepis nana & $20(6.8)$ & $19(6.6)$ & $39(6.7)$ & $1.00(0.99,1.0)$ \\
\hline Giardia lamblia & $21(7.2)$ & $12(4.2)$ & $33(5.7)$ & $0.15(0.12,0.18)$ \\
\hline Trichuris trichiura & $14(4.8)$ & $7(2.4)$ & $21(3.6)$ & $0.18(0.15,0.21)$ \\
\hline Hook worm & $5(1.7)$ & $8(2.8)$ & $13(2.2)$ & $0.41(0.38,0.45)$ \\
\hline Taenia species & $2(0.7)$ & $3(1.0)$ & $5(0.9)$ & $0.68(0.64,0.71)$ \\
\hline Entamoeba histolytica/dispar & $5(1.7)$ & $3(1.0)$ & $8(1.4)$ & $0.71(0.67,0.75)$ \\
\hline Enterobius vermicularis & $1(0.3)$ & $4(1.4)$ & $50.9)$ & $0.21(0.17,0.24)$ \\
\hline Strongyloides stercoralis & $2(0.7)$ & $6(2.1)$ & $8(1.4)$ & $0.16(0.13,0.19)$ \\
\hline Overall & $156(53.2)$ & $135(47.2)$ & $291(50.9)$ & \\
\hline
\end{tabular}

*Figures in parenthesis indicate percentages.

TABLE 3: Association of S. mansoni infection with open water sources contact habit of students $(n=579)$ of Gorgora Elementary School, Northwest Ethiopia, October 2010-November 2010.

\begin{tabular}{|c|c|c|c|c|}
\hline Risk factors & Positive for S. mansoni no. (\%) & $P$ value & COR $(95 \% \mathrm{CI})$ & $\operatorname{AOR}(95 \% \mathrm{CI})$ \\
\hline \multicolumn{5}{|c|}{ Swimming in open water } \\
\hline Yes & $116(20.03)$ & 0.00 & $4.51(1.38,14.73)$ & $4.51(1.38,14.73)$ \\
\hline No & $3(0.52)$ & & 1.00 & 1.00 \\
\hline \multicolumn{5}{|c|}{ Washing clothes in open water } \\
\hline Yes & $117(20.20)$ & 0.00 & $15.89(3.86,65.40)$ & $15.89(3.86,65.40)$ \\
\hline No & $2(0.35)$ & & 1.00 & 1.00 \\
\hline \multicolumn{5}{|c|}{ Washing utensil in open water } \\
\hline Unprotected & $79(13.64)$ & 0.95 & $1.88(1.23,2.86)$ & $2.076(1.19,3.62)$ \\
\hline Protected & $40(6.91)$ & & 1.00 & 1.00 \\
\hline \multicolumn{5}{|c|}{ Bare foot on agricultural activities } \\
\hline Yes & $100(17.27)$ & 0.04 & $4.7(2.78,7.93)$ & $7.08(3.82,13.12)$ \\
\hline No & $19(3.28)$ & & 1.00 & 1.00 \\
\hline \multicolumn{5}{|c|}{ Awareness of bilharzia } \\
\hline No & $114(19.69)$ & 0.00 & $20.36(8.16,0.78)$ & $20.36(8.16,50.78)$ \\
\hline Yes & $5(0.86)$ & & 1.00 & 1.00 \\
\hline \multicolumn{5}{|c|}{ Frequency of swimming/open water, contact habits } \\
\hline Daily & $103(17.79)$ & 0.03 & $2.02(1.15,3.57)$ & $2.02(1.15,3.57)$ \\
\hline Weekly & $16(2.76)$ & & 1.00 & 1.00 \\
\hline Overall & $119(20.55)$ & & & \\
\hline
\end{tabular}

including Ethiopia. Depending on various reasons, the prevalence of $S$. mansoni is ranging from less than $1 \%$ up to more than $90 \%$ in Ethiopia [3, 9].

In the present study the overall prevalence of $S$. mansoni among Gorgora Elementary school students was 20.6\%. This is comparable with the study conducted among students in rural area close to the South East of Lake Langano (21.2\%) [10] and South Wollo (24.9\%) [11]. However, the present study showed lower rate $(20.6 \%)$ of prevalence of S. mansoni compared to earlier reports from the same area at different years to be $67 \%$ [12] and 29\% [13]. The reason why S. mansoni infection was higher in Gorgora before when compared to the present finding might be due to lower student age groups (little school ages) which were not exposed frequently with the Lake or other water bodies and deworming exercise prior to this study [14]. Changing of Lake water level and creating dry lands devoid of vegetation which limit the breeding ground of the Mollusca also contribute to the low prevalence of the current study. This justification was also supported by the Boelee and Madsen study of the fluctuation of water level causing removal of aquatic vegetation and silt intermediate host snail. Thus, removal of aquatic plants would affect snails directly and under certain circumstance expose them to predators [15]. 
TABLE 4: Intensity of $S$. mansoni and other common intestinal helminthes using Kato-thick smear technique among students of Gorgora Elementary School, Northwest Ethiopia, October 2010November 2010.

\begin{tabular}{lccc}
\hline \multirow{2}{*}{ Species of parasites } & \multicolumn{3}{c}{ Intensity of infection (EPG) } \\
& Light & Moderate & Heavy \\
\hline Schistosoma mansoni & $76(13.1)^{*}$ & $41(7.1)$ & $2(0.3)$ \\
Ascaris lumbricoides & $97(16.8)$ & $12(2.1)$ & $0(0)$ \\
Trichuris trichiura & $21(3.6)$ & $0(0)$ & $0(0)$ \\
Hook worm & $13(2.2)$ & $0(0)$ & $0(0)$ \\
\hline Total & $\mathbf{2 0 7 ( 3 5 . 8 )}$ & $\mathbf{5 3 ( 9 . 2 )}$ & $\mathbf{2 ( 0 . 3 )}$ \\
\hline
\end{tabular}

${ }^{*}$ Figures in parenthesis indicate percentages.

This study has shown higher prevalence rate compared to earlier surveys conducted in students in Ethiopia, Babile 4.3\% [16], Gondar 16.4\% [17], and Abaya 4\% [18]. This difference might be due to the focal distribution of S. mansoni [19] and close proximity of schools in Gorgora town to Lake Tana. The present study showed lower S. mansoni infection compared to other studies conducted in different localities in Ethiopia such as: Zeghie (69.7\%) [20], Azezo 43.5\% [21], Dembia plains 35.8\% [22], Methehara 71\% [23], Zarima (37.9\%) [24], and Dek (69\%) [12]. This variation can be explained by the fact that environmental factors that influence snail distribution should not be overlooked, despite the fact that these can vary considerably from site to site and area to area, even within short distances [25].

Age specific prevalence of $S$. mansoni in the present study showed that students whose age groups ranged from 15-19 and 10-14 were highly affected and the prevalence in these age groups was $22 \%$ and $20 \%$, respectively, but in some studies the age range was $10-14[26,27]$. S. mansoni infections in female and male students was $22 \%$ and $18.4 \%$, respectively. This result was in line with the study conducted from primary school children near Lake Victoria of Kenya in which the prevalence was slightly higher in females [28]. The observed variation in the present study might be due to high tendency of open water source exposure among females because mostly they are doing the household activities such as fetching water and washing clothes. However, this remains to be further elucidated.

Site specific prevalence of $S$. mansoni revealed the higher prevalence from urban $(23.9 \%)$ and followed by rural areas (17\%). Students living in urban areas were 1.89 times (95\% CI: $1.07,3.3)$ more likely to get $S$. mansoni infection than there in rural areas. The reason might be due to high tendency of urban exposure to open water access which is found near the shore of Lake Tana and more contaminated water due to poor sanitation in urban area. This reason supported by the relationship between intensity of schistosomiasis infection and proximity of the location to water bodies has been reported from other locations in Ethiopia [29].

In grade 5-8 students, they were 2.64 times (95\% CI: 1.49 , 4.66) more likely to acquire $S$. mansoni infection. The reason might be that students at this age had higher exposure to keep their personal hygiene in unsafe open water sources.
Water contact habits of the study subjects confirmed that swimming and washing clothes and utensil in open water source are the risk factors for S. mansoni infection. Children who practice swimming are particularly at high risk maybe because of their prolonged and complete body exposure. This is similar to a study done in western Uganda's children (36\%) who depend on carter water unknowingly becoming infected while swimming, fishing, and fetching water for domestic use [30]. Those students who had frequency of swimming daily were 2.02 times (95\% CI: 1.15, 3.57) more likely to acquire S. mansoni infection than those swimming weekly. Longer periods and frequent exposure to inshore areas increase the probability of being infected by cercariae. This finding agreed with the study conducted in Brazil where a daily contact of open water source results in higher rate of infection by S. mansoni [31]. Students with bare foot during agricultural activities were 7.08 times (95\% CI: 3.82, 13.12) more likely to acquire infection. This might be due to the involvement of students in urban agricultural activities near Lake Tana. Similar finding was reported in Tigray where S. mansoni infection was higher in people living in the irrigation site [32].

Among 579 students interviewed $62 \%$ of them were without any knowledge of schistosomiasis. Students who had no awareness were 20.36 times (95\% CI: $8.16,50.78)$ more likely to acquire infection. The reason might be that the students were not conscious about the epidemiology of this disease either informally or formally through their school curriculum. This in turn may cause not only increased infection but also decreased interest of people from seeking medical treatment. Even though sex was not statistically significant, females are more likely infected and not knowledgeable of schistosomiasis compared to males. Similar studies showed that low awareness about schistosomiasis increases the risk of infection [33].

\section{Conclusions and Recommendations}

This study showed that $S$. mansoni was still an important health problem among school children at Gorgora Elementary School. Factors such as urban residence, grade, and open water contact practice: swimming and washing clothes in open water, frequent swimming, washing utensil by open water, bare foot during agricultural activities, and low awareness of schistosomiasis were associated risk factors for $S$. mansoni infection. Therefore, the well being of school age children must be made a matter of utmost priority by the health planner and decision maker and continuous effort must be geared towards the strengthening of health systems by advocating health education, strengthening of basic infrastructure and sanitation, and community involvement which are important components of successful disease control programmes.

\section{Conflict of Interests}

All authors declare that they have no conflict of interests in relation to their work. 


\section{Authors' Contributions}

T. Essa conceived the study, undertook statistical analysis, and drafted the initial and final draft paper. Y. Berhane and A. Moges reviewed the initial and final drafts of the paper. M. Endris participated in sample collection, performed laboratory diagnosis, conducted data analysis, and drafted the initial and final draft paper. F. Moges performed statistical analysis and drafted the initial and final draft paper. All authors contributed to the writing of the paper and approved the submitted version of the paper.

\section{Acknowledgments}

The authors would like to thank the study participants, Staff of Gorgora Elementary School, Amhra region Health Bureau, Dembia district health office, Mr. Aschalew Gelaw, the Department of Microbiology, Immunology, and Parasitology and the University of Gondar for their kind cooperation and support. Their thanks also go to Gorgora Clinic staff for their involvement in treating infected students.

\section{References}

[1] M. Cheesbrough, Medical Laboratory Manual for Tropical Countries, vol. 1, Cambridge University, London, UK, 2nd edition, 2001.

[2] World Health Organization, Basic Laboratory Methods in Medical Parasitology, WHO, Geneva, Switzerland, 1991.

[3] S. Tedla and L. Jemaneh, "Schistosomiasis and its distribution in Ethiopia and Eritrea," in Schistosomiasis in Ethiopia and Eritrea, H. Birrie, S. Tedela, and L. Jemaneh, Eds., pp. 1-18, Institute of Pathobiology Addis Ababa University, Addis Ababa, Ethiopia, 2nd edition, 1998.

[4] WHO Expert Committee, "Prevention and control of schistosomiasis and soil-transmitted helminthiasis," World Health Organization Technical Report Series, vol. 912, pp. 1-6, 2002.

[5] T. Harrison, "Schistomiasis other trematode infections," in Harrison's Principles of Internal Medicine, A. Adel and F. Mohamed, Eds., pp. 1266-1271, McGraw-Hill, New York, NY, USA, 16th edition, 2005.

[6] L. R. Brunet, D. W. Dunne, and E. J. Pearce, "Cytokine interaction and immune responses during schistosoma mansoni Infection," Parasitology Today, vol. 14, no. 10, pp. 422-427, 1998.

[7] P. D. H. Molyneux, “"Neglected” diseases but unrecognised successes-challenges and opportunities for infectious disease control," The Lancet, vol. 364, no. 9431, pp. 380-383, 2004.

[8] P. J. Hotez, D. H. Molyneux, A. Fenwick, E. Ottesen, S. E. Sachs, and J. D. Sachs, "Incorporating a rapid -impact package for neglected tropical disease with programs for HIV /AIDS, tuberculosis and malaria," PLoS Medicine, vol. 4, Article ID e277, 2007.

[9] A. Ali, B. Erko, T. Woldemichael, and H. Kloos, "Schistosomiasis," in Epidemiology and Ecology of Health and Diseases in Ethiopia, Y. Berhane, D. Hailemariam, and H. Kloos, Eds., vol. 1, pp. 660-673, Shama Books, Addis Ababa, Ethiopia, 2006.

[10] M. Legese and B. Erko, "Prevalence of intestinal parasites among School children in a rural area close to the Southeast of Lake Langano, Ethiopia," Ethiopian Journal of Health Development, vol. 18, pp. 116-120, 2004.
[11] T. Assefa, T. Woldemicael, and A. Dejene, "Intestinal parasitism among students in three localites in South Wello, Ethiopia," Ethiopian Journal of Health Development, vol. 12, pp. 231-235, 1998.

[12] M. Tiruneh, M. Fentahun, A. Kassu, G. Tiruneh, L. V. Lieshout, and A. M. Polderman, "Schistosomiasis mansoni in school at tenders and non-at tenders in Northwest Ethiopia," Ethiopian Journal of Health Development, vol. 15, pp. 117-123, 2001.

[13] M. Degnew, "Status of S. mansoni infection at Gorgora, Northwest Ethiopia," Ethiopian Journal of Health Development, vol. 13, pp. 15-20, 1999.

[14] G. Degu, G. Mengistu, and J. Jones, "Praziquantel efficacy against Schistosomiasis mansoni in schoolchildren in northwest Ethiopia," Transactions of the Royal Society of Tropical Medicine and Hygiene, vol. 96, no. 4, pp. 444-445, 2002.

[15] E. Boelee and H. Madsen, "Irrigation and schistosomiasis in Africa: ecological aspects," in Research Report 99, vol. 8, p. 39, International Water Management Institute, Colombo, Sri Lanka, 2006.

[16] T. Girum, "The prevalence of intestinal helminthic infections and associated risk factors among school children in Babile town, Eastern Ethiopia," Ethiopian Journal of Health Development, vol. 19, pp. 140-147, 2005.

[17] L. Jemaneh and C. Lengeler, "The use of morbidity questionnaires to identify communities with high prevalence of geohelminth infections in Gondar region, Ethiopia," Ethiopian Medical Journal, vol. 39, no. 3, pp. 213-228, 2001.

[18] T. Wodemichael, T. Endeshaw, T. Shibre, T. Gebre, M. Haddis, and D. Tilahun, "Intestinal parasitic infections in western Abaya with special reference to Shistosoma mansoni," Ethiopian Journal of Health Development, vol. 13, pp. 25-26, 1999.

[19] M. Booth, B. J. Vennervald, L. C. Kenty et al., "Microgeographical variation in exposure to Schistosoma mansoni and malaria, and exacerbation of splenomegaly in Kenyan schoolaged children," BMC Infectious Diseases, vol. 4, article 13, 2004.

[20] B. Erko and S. Tedla, "Intestinal helminth infections at Zeghie town, Ethiopia, with emphasis on Schistosoma mansoni," Ethiopian Journal of Health Development, vol. 7, pp. 21-26, 1993.

[21] M. Endris, W. Lemma, Y. Belyhun et al., "Prevalence of intestinal parasites and associated risk factors among students of Atse Fasil General Elementary School Azezo, Northwest Ethiopia," Ethiopian Journal of Health and Biomedical Sciences, vol. 3, pp. 25-33, 2010.

[22] L. Jemaneh, "Schistosomiasis mansoni and geo-helminthiasis in school children in the Dembia plains, Northwest Ethiopia," Ethiopian Journal of Health Development, vol. 12, pp. 237-244, 1998.

[23] F. Abebe, S. Tedla, H. Birrie, and G. Medhin, “Transmission dynamics of Schistosoma mansoni in an irrigation setting in Ethiopia," Ethiopian Journal of Health Development, vol. 9, pp. 147-156, 1995.

[24] A. Alemu, A. Atnafu, Z. Addis et al., "Soil transmitted helminths and Schistosoma mansoni infections among school children in Zarima town, northwest Ethiopia," BMC Infectious Diseases, vol. 11, p. 189, 2011.

[25] T. P. Pesigan, N. G. Hairston, J. J. Jauregui et al., "Studies on Schistosoma japonicum infection in the Philippines. The molluscan host," Bulletin of the World Health Organization, vol. 18, pp. 481-578, 1958.

[26] C. S. Barbosa, T. C. Favre, T. N. Wanderley, A. C. Callou, and O. S. Pieri, "Assessment of schistosomiasis, through school 
surveys, in the Forest Zone of Pernambuco, Brazil," Memorias do Instituto Oswaldo Cruz, vol. 101, no. 1, pp. 55-62, 2006.

[27] R. D. C. R. Silva, M. L. Barreto, A. M. O. Assis et al., "The relative influence of polyparasitism, environment, and host factors on schistosome infection," American Journal of Tropical Medicine and Hygiene, vol. 77, no. 4, pp. 672-675, 2007.

[28] T. Handzel, D. M. Karanja, D. G. Addiss et al., "Geographic distribution of schistosomiasis and soil-transmitted helminths in Western Kenya: implications for anthelminthic mass treatment," The American Journal of Tropical Medicine and Hygiene, vol. 69, no. 3, pp. 318-323, 2003.

[29] L. Jemaneh, "Intestinal helminth infections in school children in Gondar Town and surrounding areas, Northwest Ethiopia," SINET: Ethiopian Journal of Science, vol. 22, pp. 209-220, 1999.

[30] R. John, M. Ezekiel, C. Philbert, and A. Andrew, "Schistosomiasis transmission at high altitude crater lakes in Western Uganda," BMC Infectious Diseases, vol. 8, article 110, 2008.

[31] O. Marçal Júnior, L. K. Hotta, R. M. Patucci, C. M. Glasser, and L. C. Dias, "Schistosomiasis mansoni in an area of low transmission. II. Risk factors for infection," Revista do Instituto de Medicina Tropical de Sao Paulo, vol. 35, no. 4, pp. 331-335, 1993.

[32] D. Tadese and P. Beyne, "Irrigation practice and Intestinal Helminth infection in Southern and central zone of Tigray Ethiopia," Ethiopian Journal of Health Development, vol. 23, pp. 48-56, 2009.

[33] V. T. Schall, "An interactive perspective of health education for the tropical disease control: the schistosomiasis case," Memorias do Instituto Oswaldo Cruz, vol. 93, pp. 51-58, 1998. 


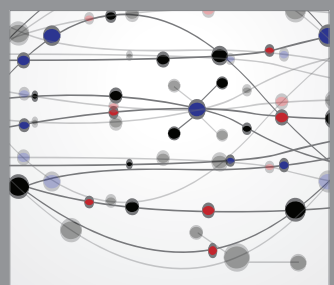

The Scientific World Journal
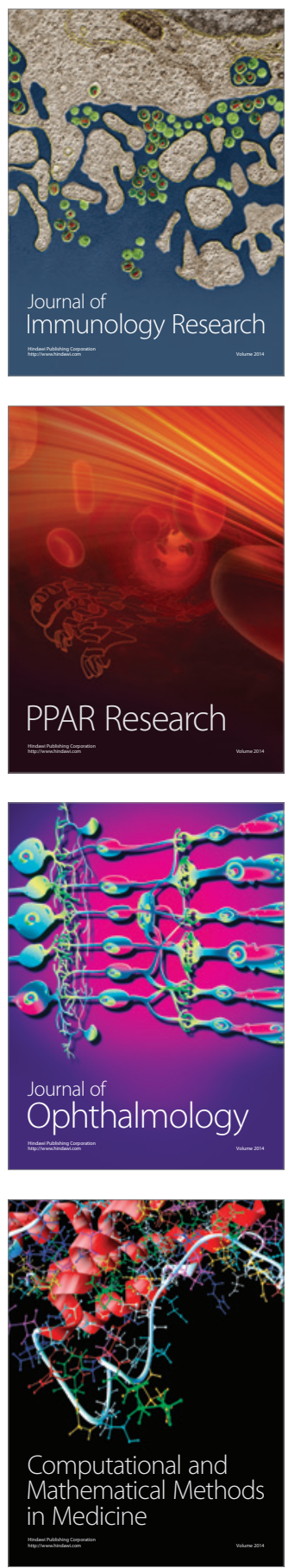

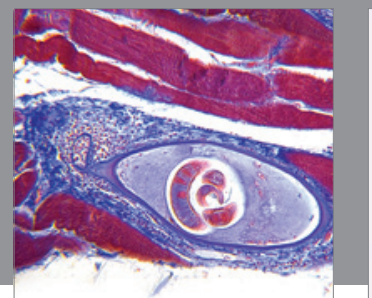

Gastroenterology

Research and Practice
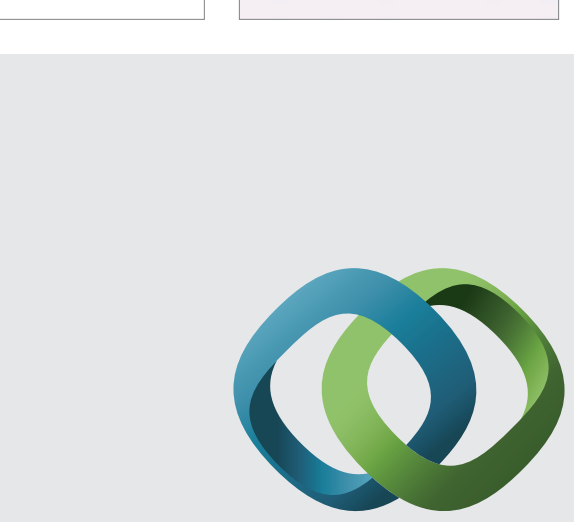

\section{Hindawi}

Submit your manuscripts at

http://www.hindawi.com
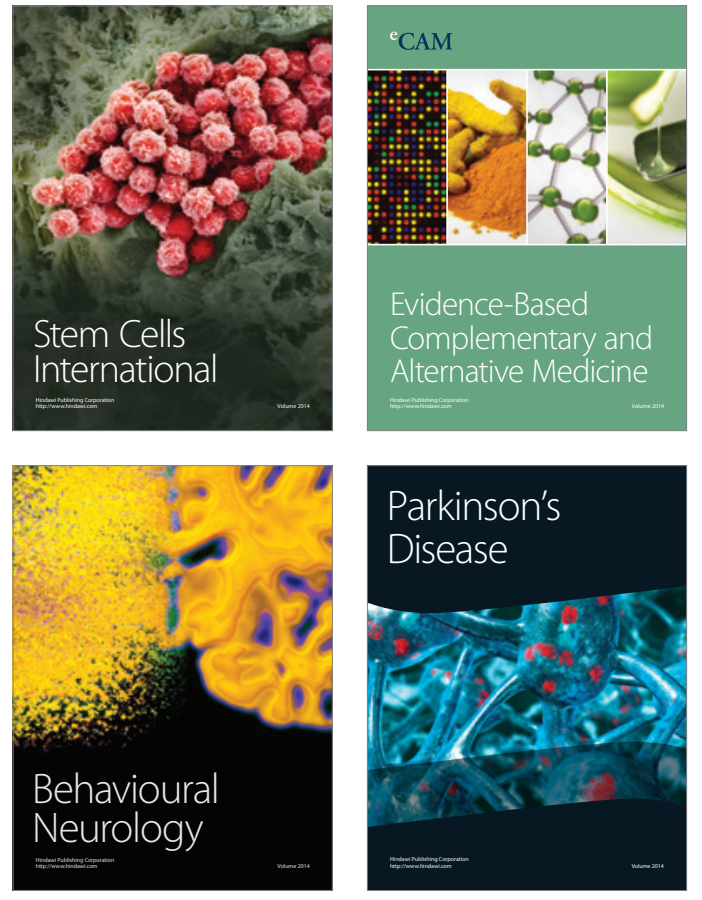
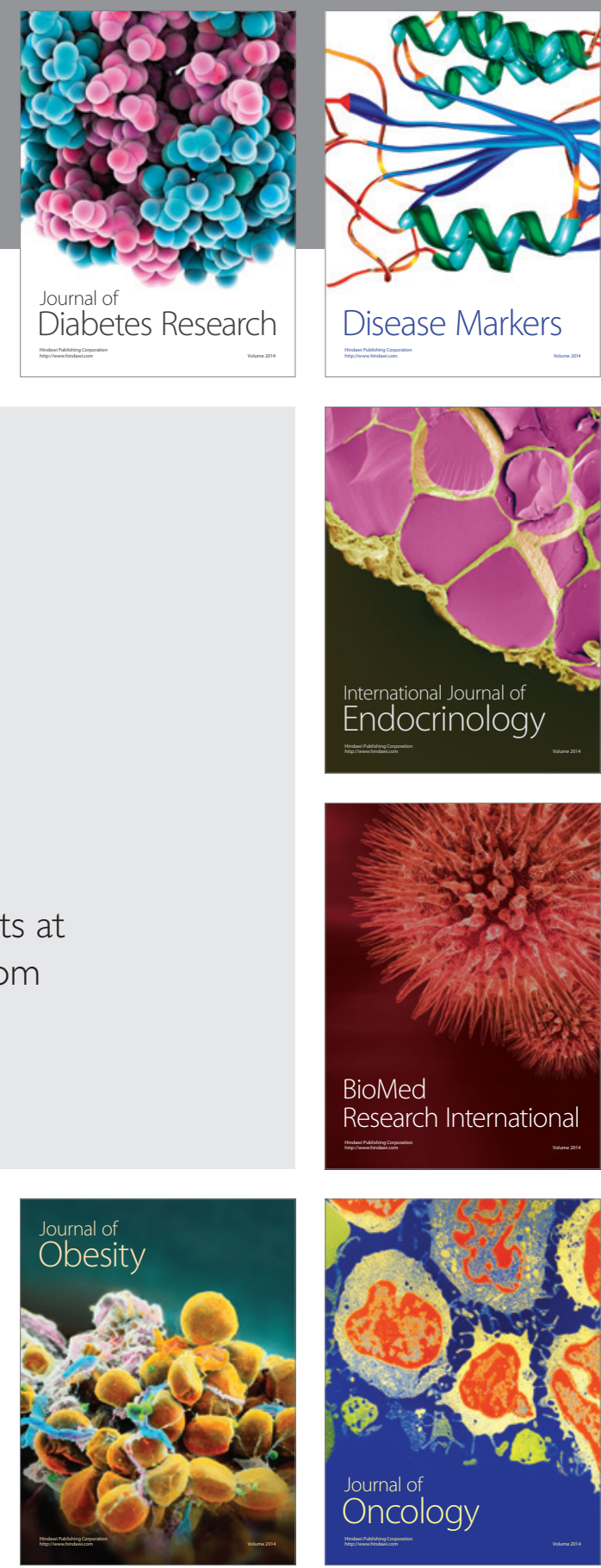

Disease Markers
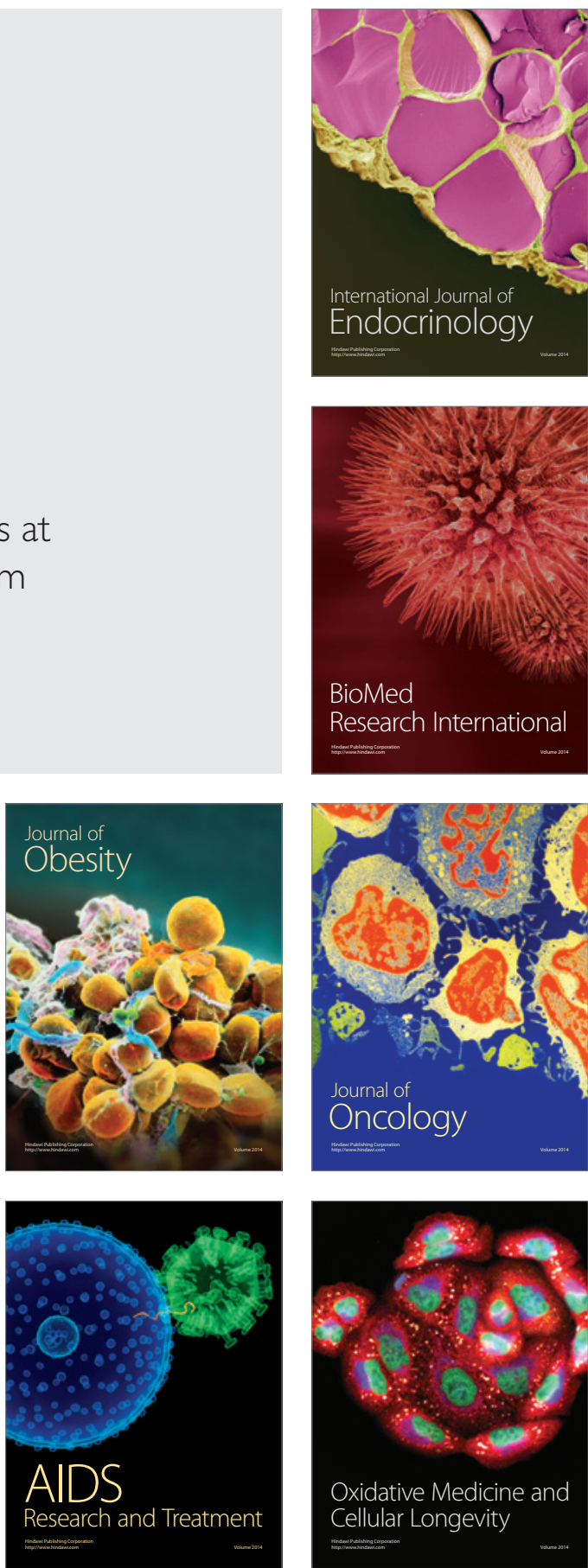